ISSN = 1980-993X-doi:10.4136/1980-993X
www.agro.unitau.br/ambi-agua
E-mail: ambi-agua@agro.unitau.br
Tel.: (12) 3625-4116

\title{
Aplicação do TOPMODEL para determinação de áreas saturadas da bacia do rio Pequeno, São José dos Pinhais, PR, Brasil \\ (doi:10.4136/ambi-agua.54)
}

\author{
Irani dos Santos ${ }^{1}$; Masato Kobiyama ${ }^{2}$ \\ ${ }^{1}$ Departamento de Geografia, Universidade Federal do Paraná \\ E-mail: irani@ufpr.br \\ ${ }^{2}$ Departamento de Engenharia Sanitária e Ambiental, Universidade Federal de Santa Catarina \\ E-mail: kobiyama@ens.ufsc.br
}

\section{RESUMO}

O presente trabalho mostra a aplicação do modelo hidrológico TOPMODEL para determinar as áreas saturadas da bacia hidrográfica do rio Pequeno, com área de $104 \mathrm{~km}^{2}$, localizada no município de São José dos Pinhais, Região Metropolitana de Curitiba, Paraná. O TOPMODEL pressupõe que a dinâmica da água é influenciada pelas características do solo e do relevo de toda a bacia contribuinte, fornecendo como resultado, além da vazão do rio, a distribuição espacial da umidade no sistema (zonas saturadas e áreas secas) ao longo do tempo. Os mapas de áreas saturadas foram analisados frente ao uso do solo e às áreas de preservação permanente de mata ciliar. O TOPMODEL apresentou boa aderência entre as vazões observadas e calculadas $\left(\mathrm{R}^{2}=0,75\right)$, confirmando sua eficiência em regiões de clima úmido e relevo suave. Os resultados das simulações mostram o grande potencial de aplicabilidade desse modelo no planejamento ambiental, pois permitem discutir e orientar as ações antrópicas sobre o meio físico com base no entendimento dos processos naturais.

Palavras-chave: TOPMODEL; área saturada; planejamento ambiental.

\section{Determination of saturated areas using TOPMODEL in the Pequeno river watershed, Southern Brazil}

\begin{abstract}
This work presents the determination of saturated areas in the Pequeno River watershed $\left(104 \mathrm{~km}^{2}\right)$, located in the São José dos Pinhais District, Metropolitan Region of Curitiba, Paraná State, Brazil. We employed the hydrological model TOPMODEL which assumes that the water dynamics are influenced by soil and hillslope characteristics of the entire watershed. It calculates the runoff and the spatial distribution (saturated and unsaturated areas) of the soil humidity in the system throughout the considered time period. The maps of the saturated areas were analyzed taking into account the land use and riparian vegetation (permanent preservation). The computations showed a good adherence between calculated and observed runoff $\left(\mathrm{R}^{2}=0.75\right)$, thus confirming the model efficiency in regions of humid climate and smooth topography. The simulation results reveal a potential application for environmental planning because they allow the discussion and further orientation for human interventions in the environment based on the understanding of the natural processes.
\end{abstract}

Keywords: TOPMODEL; saturated area; environmental planning. 


\section{INTRODUÇÃO}

As distribuições espaciais e temporais dos recursos hídricos vêm se tornando mais heterogêneas devido à ação humana intensa e sem planejamento correto, prejudicando os sistemas naturais e a própria sociedade. No Brasil, a bacia hidrográfica foi definida, de acordo com a Lei Federal N 9433/97, como “a unidade territorial para implantação da Política Nacional de Recursos Hídricos e a atuação do Sistema Nacional de Gerenciamento de Recursos Hídricos”. Esse arcabouço legal altera, também, a demanda por produção científica. Assim, estudos em bacias hidrográficas tornam-se fundamentais para o planejamento ambiental.

A bacia do rio Pequeno, com uma área de $134 \mathrm{~km}^{2}$, localiza-se no município de São José dos Pinhais, na região metropolitana de Curitiba, estado do Paraná, Brasil. Devido ao crescimento populacional acelerado da região, essa bacia vem sofrendo pressões ambientais, principalmente pela expansão da ocupação urbana sem planejamento. Nesse contexto, tornase necessário um zoneamento ambiental com base em conhecimento técnico relativo aos processos naturais atuantes na bacia.

O procedimento para estabelecer tal zoneamento é complexo e requer tempo, recursos humanos e financeiros, sendo, portanto, vantajosa a utilização de técnicas de modelagem computacional. Os modelos que tratam dos processos precipitação-vazão apresentam grande capacidade de representar conceitualmente a dinâmica da água em bacias hidrográficas. A modelagem desses processos pressupõe o conhecimento detalhado do ciclo hidrológico dentro de uma bacia hidrográfica. Com base no conhecimento desses processos, surgiu o conceito de área variável de afluência e o fluxo subsuperficial foi reconhecido como um dos processos mais importantes na geração do escoamento (Kirkby, 1978), pela própria contribuição do escoamento de retorno e a sua influência preponderante no escoamento direto.

Considerando que a topografia apresenta uma grande influência no movimento de água subterrânea e que controla igualmente o movimento de água na superfície, pode-se fundamentar um modelo de dinâmica de bacias na idéia de que a topografia é a característica de paisagem mais importante no controle do fluxo de água. Essas considerações tornam o relevo um elemento importante no ciclo hidrológico e permitiram o desenvolvimento de modelos que levassem em consideração esses processos, sendo o TOPMODEL (Beven e Kirkby, 1979) um dos mais difundidos entre os que possuem essa característica.

O TOPMODEL é um modelo do tipo determinístico, semidistribuído e fisicamente baseado. Esse modelo pressupõe que a dinâmica da água resulta das características do solo e do relevo de toda a bacia contribuinte, o que fornece como resultado, além da vazão do rio, a distribuição espacial da umidade no sistema (zonas saturadas e áreas secas) ao longo do tempo, e permite estimar por meio de calibragem valores característicos de algumas propriedades físico-hídricas do solo (por exemplo, transmissividade).

Em sua formulação, o TOPMODEL utiliza relações físicas para reproduzir o comportamento de alguns dos processos hidrológicos e também para representar a bacia hidrográfica. Com base em Beven et al. (1995), Mine e Clarke (1996), Beven (1997), Tucci (1998), Hornberger et al. (1998) e Beven (2001), Santos (2001) sintetizou um resumo da base conceitual do modelo, cujos principais componentes são: armazenamentos e fluxos na zona não-saturada; armazenamentos e fluxos na zona saturada; e propagação do fluxo na sub-bacia. O modelo considera as seguintes hipóteses: 
(1) A dinâmica da zona saturada pode ser obtida por sucessivas representações de estados uniformes.

(2) O gradiente hidráulico da zona saturada é igual a declividade local do terreno.

(3) A distribuição da transmissividade com a profundidade do solo ocorre segundo uma função exponencial.

(4) No intervalo de tempo existe homogeneidade espacial da taxa de recarga que contribui para a área saturada.

O presente trabalho mostra a aplicação do modelo hidrológico TOPMODEL para determinar as áreas saturadas da bacia hidrográfica do rio Pequeno.

\section{MATERIAL E MÉTODOS}

\section{1. Área de estudo}

A bacia hidrográfica do rio Pequeno está compreendida integralmente nos limites do município de São José dos Pinhais, entre as coordenadas $25^{\circ} 29^{\prime}$ e $25^{\circ} 37^{\prime}$ de latitude sul e os meridianos $48^{\circ} 58^{\prime}$ e $49^{\circ} 11^{\prime}$ de longitude oeste. A área total de drenagem é de $134 \mathrm{~km}^{2}$, tendo como limites, ao norte, a bacia do rio Itaqui, ao sul, a bacia do rio Miringuava, a leste, o relevo montanhoso da Serra do Mar e a oeste, o rio Iguaçu.

A bacia está localizada no Primeiro Planalto Paranaense (Maack, 1968), com as nascentes localizadas na encosta ocidental da Serra do Mar sobre a formação geológica de migmatitos e granitos associados do período pré-cambriano. Desenvolve-se no sentido geral leste-oeste atravessando a formação Guabirotuba do pleistoceno, indo desaguar no rio Iguaçu, que possui em suas planícies sedimentos recentes (holoceno) denominados aluviões (CODEPAR, 1967).

A bacia do rio Pequeno, segundo a classificação de Köppen, apresenta o tipo climático Cfb que se caracteriza como "clima temperado propriamente dito; temperatura média do mês mais frio abaixo de $18^{\circ} \mathrm{C}$ (mesotérmico), com verões frescos, temperatura média no mês mais quente abaixo de $22^{\circ} \mathrm{C}$ e sem estação seca definida” (IAPAR, 1994). A precipitação média anual da região é de aproximadamente $1400 \mathrm{~mm}$, bem distribuídos ao longo do ano.

A Figura 1 mostra a localização da bacia hidrográfica do rio Pequeno, destacando também a localização dos pontos de monitoramento localizados na bacia: estação pluviométrica Chácara Guajubi (Código: 02549123, localizada nas coordenadas 25³3’ de latitude sul e $49^{\circ} 04^{\prime}$ de longitude oeste) e estação fluviométrica Fazendinha (Código: 65010000, nas coordenadas $25^{\circ} 31^{\prime}$ de latitude sul e $49^{\circ} 11^{\prime}$ ' de longitude oeste). O presente trabalho considera a "bacia hidrográfica do rio Pequeno" como a área afluente à estação fluviométrica Fazendinha com 104 km². 

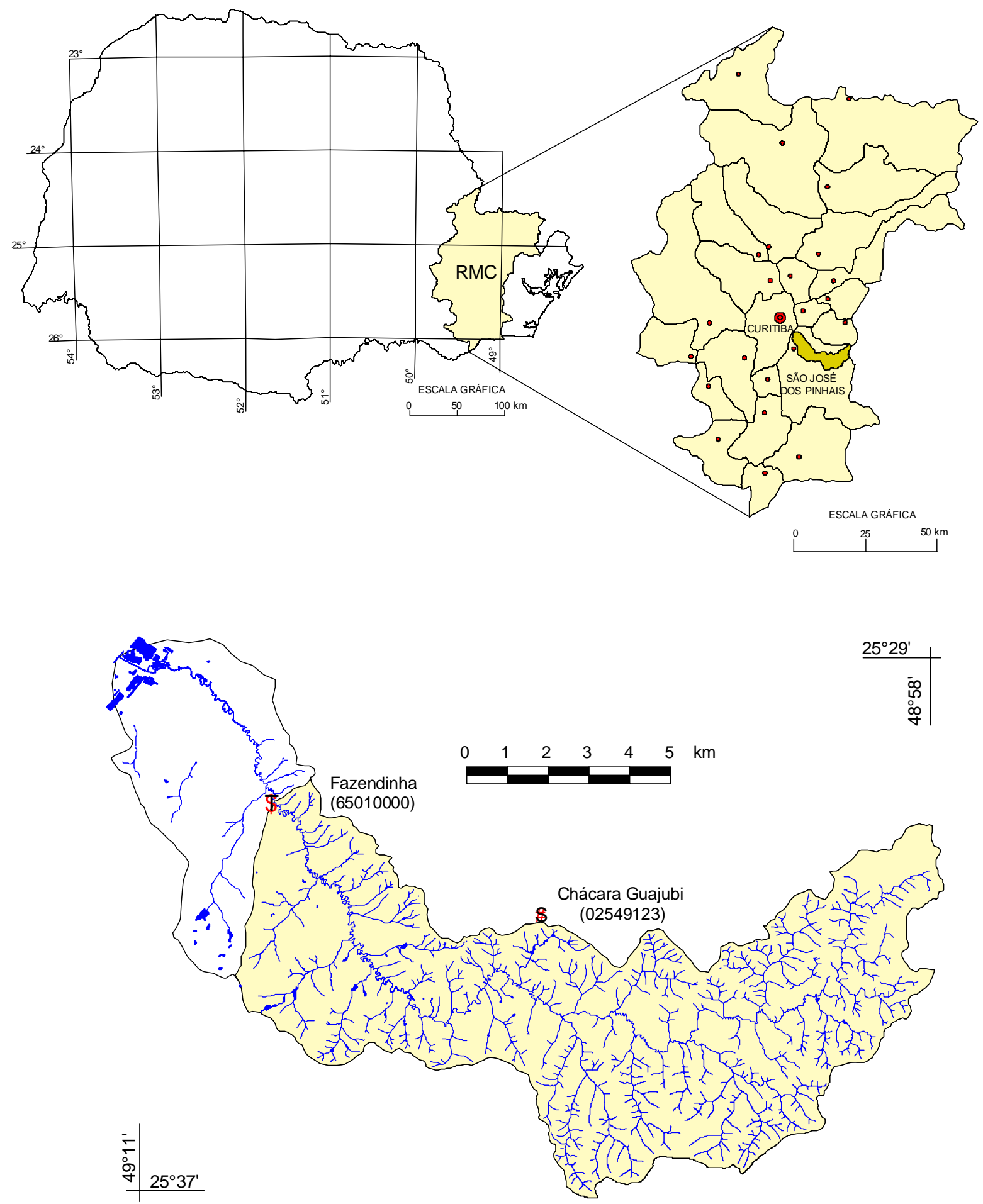

Figura 1. Localização da bacia do rio Pequeno.

\subsection{Aplicação do TOPMODEL}

O presente trabalho utilizou a versão (97.01) do TOPMODEL elaborado pela University of Lancaster (Beven, 1997). O modelo possui cinco parâmetros de entrada que exigem calibração com valores médios para a bacia (Tabela 1). 

do rio Pequeno, São José dos Pinhais, PR, Brasil. Ambi-Agua, Taubaté, v. 3, n. 2, p. 77-89, 2008. (doi:10.4136/ambi-agua.54)

Tabela 1. Parâmetros de entrada no TOPMODEL.

\begin{tabular}{c|l|c}
\hline Parâmetro & \multicolumn{1}{|c}{ Descrição } & Unidade \\
\hline$m$ & Parâmetro da função de transmissividade exponencial ou curva & $\mathrm{m}$ \\
& de recessão & \\
$\ln \left(T_{0}\right)$ & Transmissividade efetiva do solo saturado & $\mathrm{m}^{2} / \mathrm{h}$ \\
$S R_{\max }$ & Capacidade de água na zona de raízes & $\mathrm{m}$ \\
$S R_{\text {init }}$ & $\begin{array}{l}\text { Déficit de armazenamento inicial na zona de raízes (proporção } \\
\text { de } S R_{\max } \text { ) }\end{array}$ & $\mathrm{m}$ \\
$C h V e l$ & Velocidade da propagação superficial (assume propagação & $\mathrm{m} / \mathrm{h}$ \\
& linear)
\end{tabular}

O modelo utiliza também dois parâmetros de bacia, distribuídos espacialmente e obtidos a partir das características geomorfológicas, um dado pela distribuição do índice topográfico e outro pelas características da bacia de propagação.

As variáveis de entrada necessárias para calibração/simulação do modelo são precipitação, vazão e evapotranspiração potencial.

Em função das características do modelo e do tamanho da área da bacia, optou-se pela utilização de dados horários. Assim, foram utilizados dados de vazões médias horárias entre agosto de 1999 e dezembro de 2000 da estação fluviométrica Fazendinha, automatizada pela Superintendência de Recursos Hídricos e Saneamento Ambiental do estado do Paraná.

Foram utilizados também na modelagem os dados horários de precipitação da estação Chácara Guajubi. Como essa estação está localizada na região central da bacia do rio Pequeno, optou-se por não fazer correção espacial da precipitação, ou seja, a precipitação observada nesse local foi considerada como sendo igual a média sobre a bacia.

A evapotranspiração potencial diária foi calculada pelo método de Penman Modificado (Doorenbos e Pruit, 1992) a partir dos dados meteorológicos diários da estação meteorológica Piraquara/Pinhais (02549041) operada pelo Instituto Tecnológico SIMEPAR, localizada no município de Pinhais com $25^{\circ} 25^{\prime}$ de latitude sul e $49^{\circ} 08^{\prime}$ de longitude oeste e altitude de $930 \mathrm{~m}$.

Para entrada no modelo, os valores de evapotranspiração diária foram convertidos em dados horários, sendo distribuídos entre os horários de maior insolação (07h às 17h) a partir de coeficientes de ponderação utilizados por Mine (1998) e mostrados na Tabela 2. A Figura 2 mostra o fluxograma de integração das atividades e dados necessários para simulação do modelo.

Tabela 2. Coeficientes de ponderação para evapotranspirações horárias.

\begin{tabular}{c|c|c|c|c|c|c|c|c|c|c|c}
\hline Hora do dia & $\mathbf{7}$ & $\mathbf{8}$ & $\mathbf{9}$ & $\mathbf{1 0}$ & $\mathbf{1 1}$ & $\mathbf{1 2}$ & $\mathbf{1 3}$ & $\mathbf{1 4}$ & $\mathbf{1 5}$ & $\mathbf{1 6}$ & $\mathbf{1 7}$ \\
\hline Coeficientes & 0,034 & 0,066 & 0,094 & 0,114 & 0,127 & 0,132 & 0,127 & 0,114 & 0,094 & 0,066 & 0,034 \\
\hline
\end{tabular}


SANTOS, I. dos; KOBIYAMA, M. Aplicação do TOPMODEL para determinação de áreas saturadas da bacia do rio Pequeno, São José dos Pinhais, PR, Brasil. Ambi-Agua, Taubaté, v. 3, n. 2, p. 77-89, 2008. (doi:10.4136/ambi-agua.54)

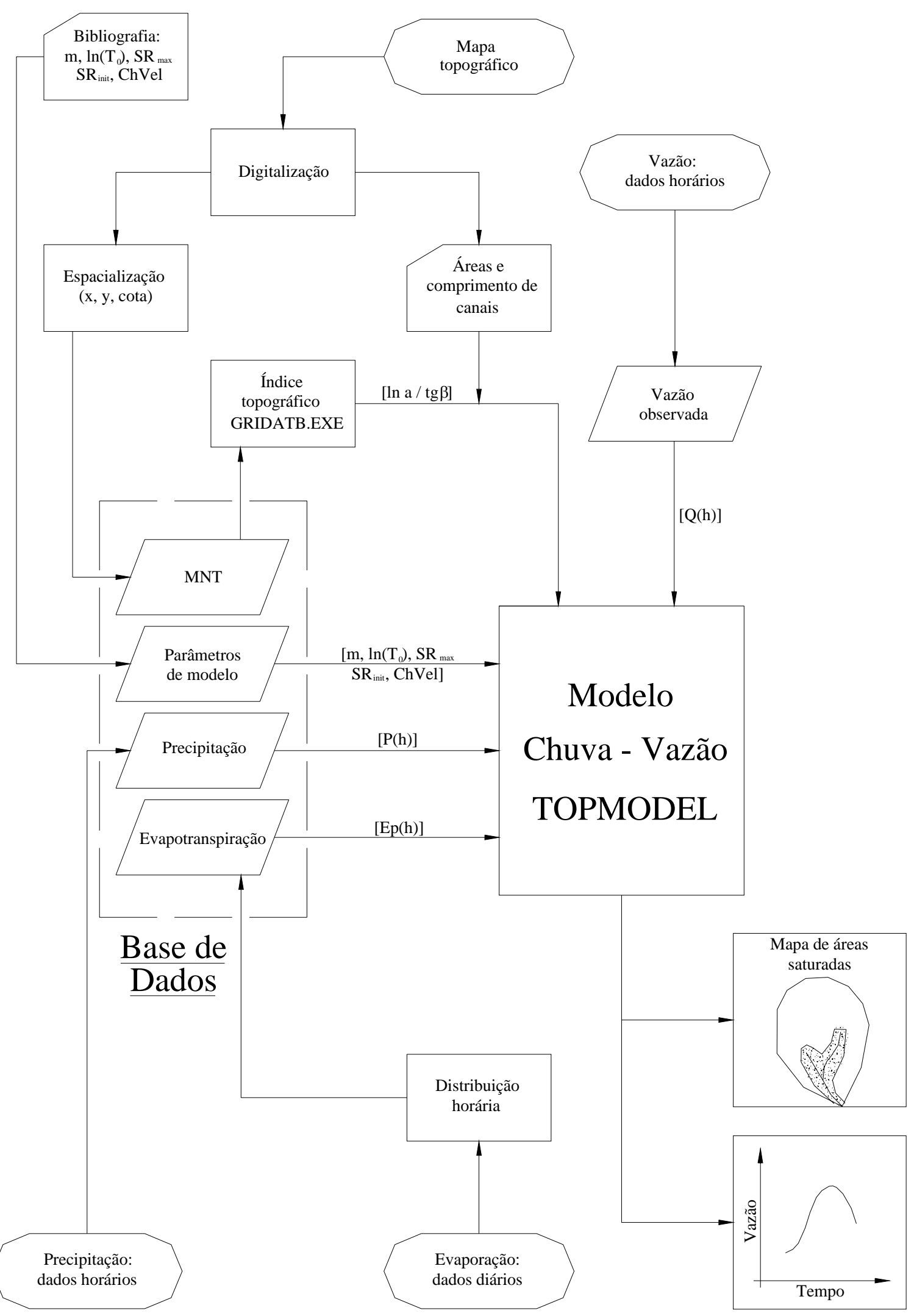

Figura 2. Fluxograma de atividades para utilização do TOPMODEL (Modificado de Varella e Campana, 2000). 


\section{RESULTADOS E DISCUSSÃO}

\subsection{Parâmetros}

A versão do TOPMODEL utilizada possui o limite de 2500 intervalos de tempo em cada simulação. Em função dessa limitação a série de dados foi dividida em seis períodos, conforme mostra a Tabela 3.

Tabela 3. Valores dos parâmetros obtidos na calibração do TOPMODEL.

\begin{tabular}{ccccccccc}
\hline Período & Início & Final & $\boldsymbol{m}$ & $\ln \left(\boldsymbol{T}_{\mathbf{0}}\right)$ & SRmax & SRinit & ChVel & $\boldsymbol{E}$ \\
\hline 1 & $14 / 08 / 99$ & $30 / 09 / 99$ & 0,030 & 0,05 & 0,0030 & 0,001 & 500 & 0,776 \\
2 & $26 / 09 / 99$ & $25 / 12 / 99$ & 0,030 & 0,05 & 0,0005 & 0,001 & 460 & 0,528 \\
3 & $22 / 12 / 99$ & $03 / 04 / 00$ & 0,070 & 0,05 & 0,0040 & 0,001 & 460 & 0,576 \\
4 & $31 / 03 / 00$ & $08 / 07 / 00$ & 0,070 & 0,05 & 0,0040 & 0,001 & 500 & 0,732 \\
5 & $05 / 07 / 00$ & $01 / 10 / 00$ & 0,024 & 0,05 & 0,0020 & 0,001 & 500 & 0,874 \\
6 & $28 / 09 / 00$ & $31 / 12 / 00$ & 0,030 & 0,05 & 0,0020 & 0,001 & 480 & 0,702 \\
\hline Média & & & $\mathbf{0 , 0 4 2}$ & $\mathbf{0 , 0 5}$ & $\mathbf{0 , 0 0 2 6}$ & $\mathbf{0 , 0 0 1}$ & $\mathbf{4 8 3}$ & $\mathbf{0 , 6 9 8}$ \\
\hline
\end{tabular}

Para cada período foi ajustado o melhor conjunto de valores dos parâmetros para a estimativa das vazões. A Tabela 3 apresenta esses valores juntamente com os valores de eficiência medidos pelo índice de Nash e Sutcliffe $(E)$.

A análise da qualidade de uma simulação é, em geral, realizada pela medida de aderência entre as vazões observadas e simuladas. O índice $E$ indica que quanto melhor o ajuste entre os dois conjuntos de valores, mais próximo de 1 é o valor $E$. Valores de $E \geq 0,7$ indicam alta eficiência no ajuste do modelo (Iorgulescu e Jordan, 1994; Mine e Clarke, 1996). De maneira geral, os valores dos parâmetros mantiveram-se coerentes com as grandezas físicas às quais estão associados.

Para o parâmetro $\ln \left(T_{0}\right)$, foi encontrado o valor de $0,05 \mathrm{~m}^{2} / \mathrm{h}$ para todos os períodos, o que representa uma transmissividade do solo de: $T_{0}=\mathrm{e}^{0,05} \cong 1,05 \mathrm{~m}^{2} / \mathrm{h}$.

Essa transmissividade equivale a condutividade hidráulica saturada de 0,03 e 0,015 $\mathrm{cm} / \mathrm{s}$ para solos com profundidade média de 1 e $2 \mathrm{~m}$, respectivamente. Esses valores são condizentes com valores obtidos em medições diretas, como mostrado a seguir.

Montgomery e Dietrich (1995) calcularam a condutividade hidráulica a partir de dados piezométricos e encontraram valores de 0,1 a $0,01 \mathrm{~cm} / \mathrm{s}$ em solos rasos e abaixo de $10^{-7}$ até $10^{-8} \mathrm{~cm} / \mathrm{s}$ em depósitos coluviais. Wu e Sidle (1995) encontraram valores de condutividade hidráulica saturada em torno de $0,8 \mathrm{~m} / \mathrm{h} \cong 0,02 \mathrm{~cm} / \mathrm{s}$ para diferentes profundidades e tipos de solo. Assim, é razoável o valor de $T_{0}$ obtido no presente trabalho, supondo-se que a profundidade do solo varia entre 1 e $2 \mathrm{~m}$.

\subsection{Hidrograma}

A Figura 3 mostra os hidrogramas das vazões horárias observadas e calculadas, a Figura 4 apresenta um gráfico com as vazões acumuladas no tempo e a Figura 5 mostra a correlação entre as vazões observadas e calculadas. Esses resultados indicam um bom ajuste do modelo à bacia estudada, com coeficiente de determinação $\mathrm{R}^{2}=0,75$ entre as vazões calculadas e observadas. 
SANTOS, I. dos; KOBIYAMA, M. Aplicação do TOPMODEL para determinação de áreas saturadas da bacia do rio Pequeno, São José dos Pinhais, PR, Brasil. Ambi-Agua, Taubaté, v. 3, n. 2, p. 77-89, 2008. (doi:10.4136/ambi-agua.54)

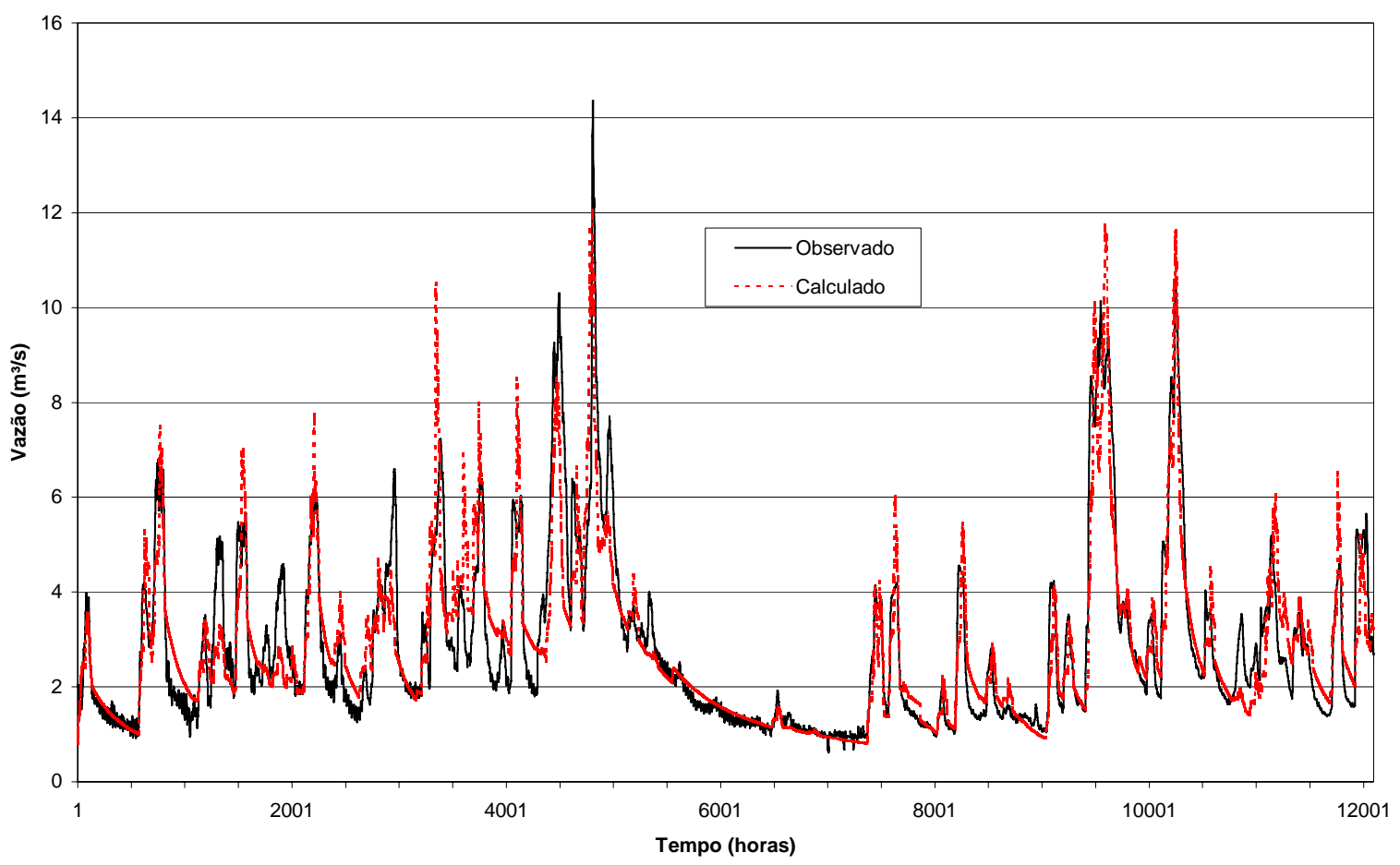

Figura 3. Hidrogramas de vazões observadas e calculadas.

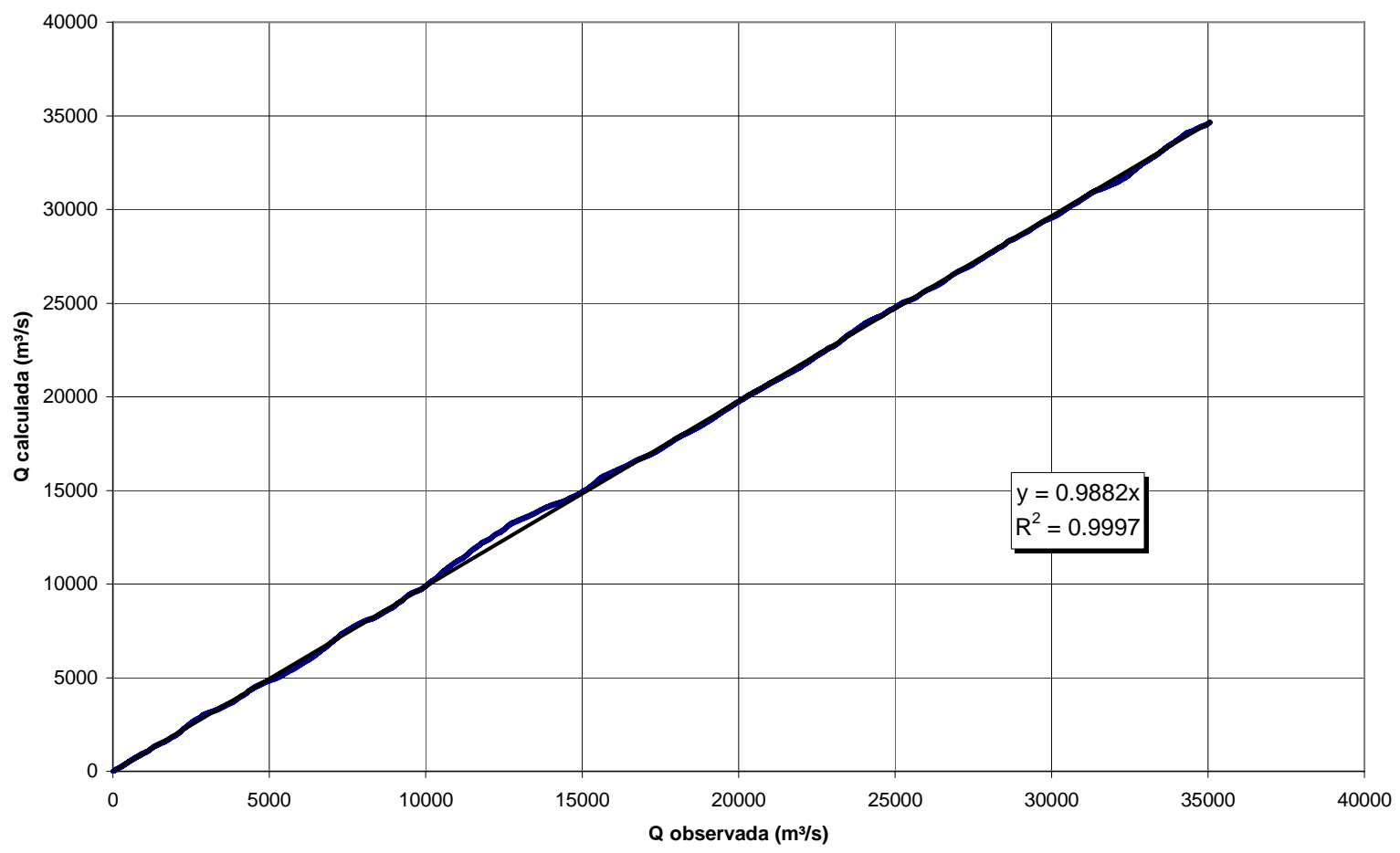

Figura 4. Vazões observadas e calculadas acumuladas no tempo. 


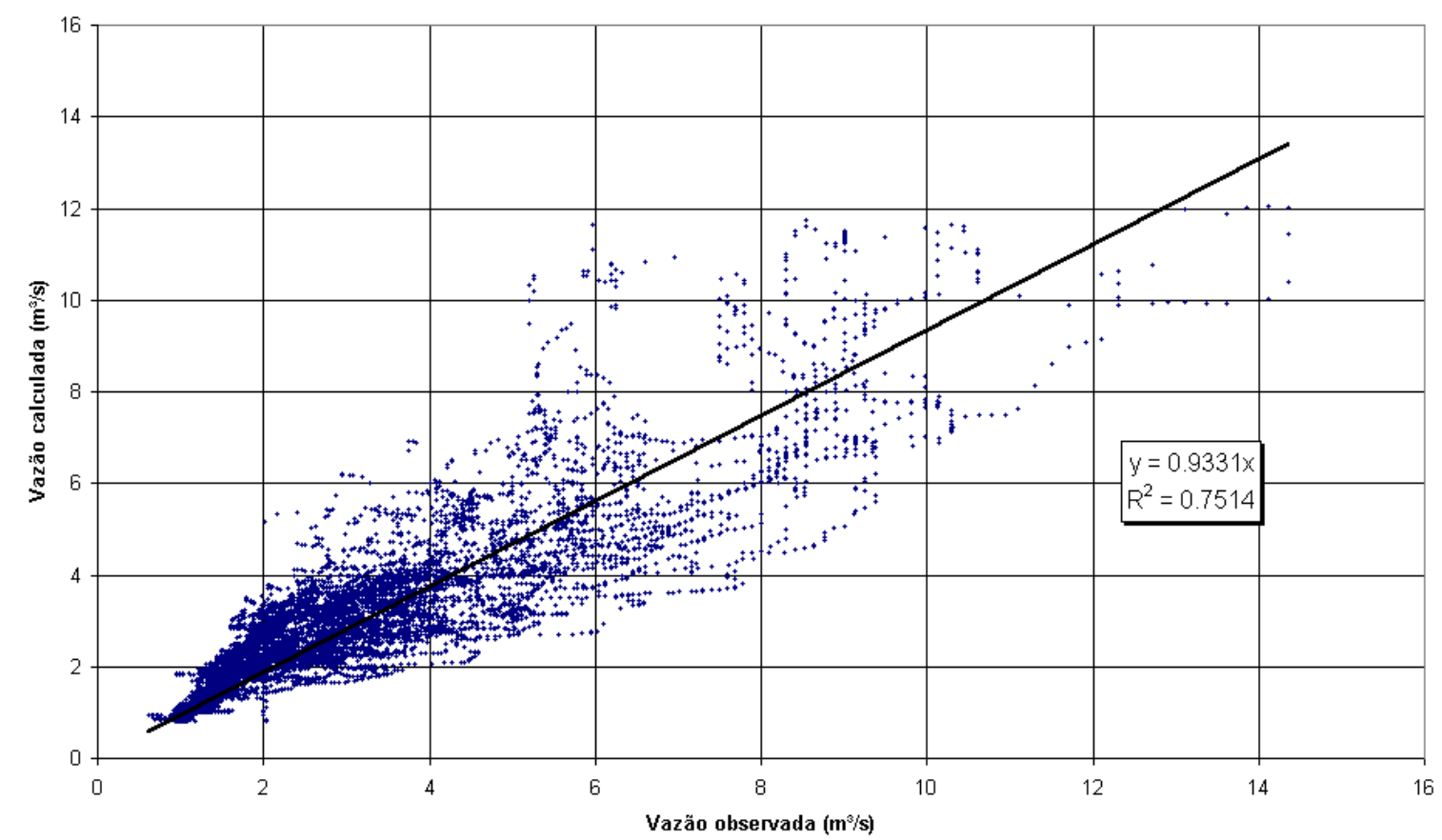

Figura 5. Coeficiente de determinação entre vazões observadas e calculadas.

\subsection{Zoneamento}

A simulação do TOPMODEL resulta também em um mapa com as áreas saturadas para cada intervalo de tempo definido na modelagem. Como o intervalo de tempo adotado foi de uma hora, obtiveram-se 12.000 mapas que reproduzem a dinâmica das áreas saturadas no tempo e no espaço. No período simulado de 14/08/99 a 31/12/00, a porcentagem de áreas saturadas em relação à área total da bacia variou entre 15,8\% e 32,8\%. A Figura 6 mostra o mapa de áreas saturadas, mínima e máxima, para o período simulado.

O valor mínimo de 15,8\% se manteve constante durante os períodos mais secos. Esse valor está coerente com o observado na bacia, pois a sua configuração topográfica favorece a formação de banhados, que estão presentes ao longo de todo o vale formado por aluviões. 

do rio Pequeno, São José dos Pinhais, PR, Brasil. Ambi-Agua, Taubaté, v. 3, n. 2, p. 77-89, 2008.

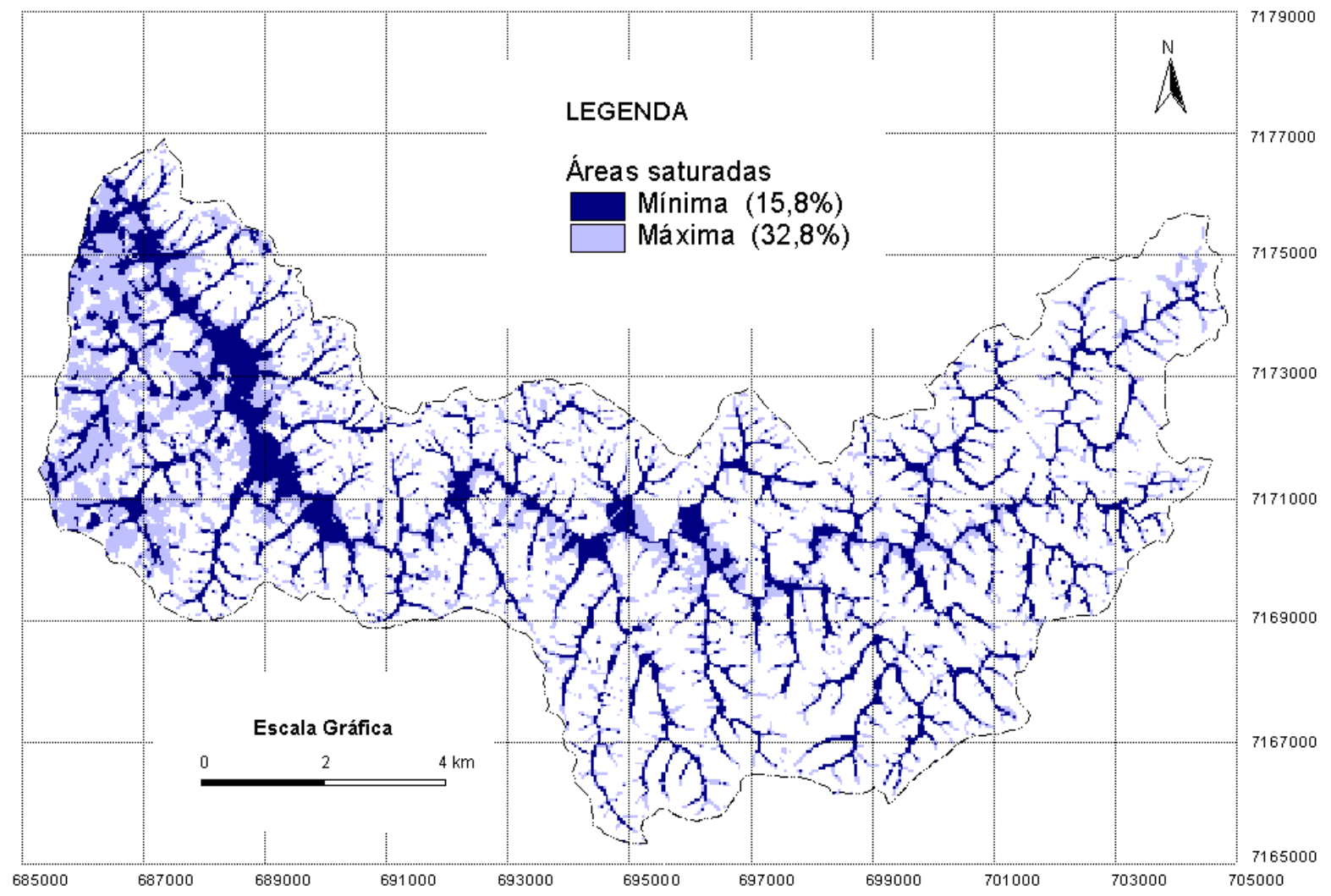

Figura 6. Mapa de áreas saturadas.

As áreas de preservação permanente correspondentes à mata ciliar da bacia do rio Pequeno possuem uma área de $21 \mathrm{~km}^{2}$, que equivale a $20 \%$ da área total da bacia (Figura 7). Comparando-se os mapas de áreas de preservação permanente e de áreas saturadas fica evidente que, em grande parte, elas não coincidem espacialmente.

Pode-se considerar que as áreas saturadas da bacia apresentam função hidrológica distinta, ou seja, toda a precipitação sobre essas áreas escoa diretamente para os cursos de água, sem passar pelos processos de infiltração e escoamento subsuperficial, o que pode provocar o carreamento de possíveis contaminantes existentes na superfície do solo diretamente para os rios.

Outro aspecto ambientalmente importante é que essas áreas apresentam uma condição de biodiversidade também distinta, com flora e fauna adaptadas às condições de permanência e/ou variação do lençol freático. Portanto, essas áreas possuem uma importante função ambiental e devem ser preservadas.

Considerando-se a possibilidade de preservação ou de uso do solo diferenciado nas áreas saturadas, a Figura 8 mostra um mapa que reúne as áreas de preservação permanente de mata ciliar, definidas por lei, com as áreas saturadas da bacia. Assim, a área de $21 \mathrm{~km}^{2}$ (20\%) equivalente às áreas de preservação permanente é acrescida de 7,95 $\mathrm{km}^{2}$ (8\%) de área permanentemente saturada (área saturada mínima) e de $12,71 \mathrm{~km}^{2}(12 \%)$ de áreas saturadas eventualmente por ocasião dos eventos de cheias (área saturada máxima), ambas localizadas fora do limite das áreas de preservação permanente. 
SANTOS, I. dos; KOBIYAMA, M. Aplicação do TOPMODEL para determinação de áreas saturadas da bacia do rio Pequeno, São José dos Pinhais, PR, Brasil. Ambi-Agua, Taubaté, v. 3, n. 2, p. 77-89, 2008. (doi:10.4136/ambi-agua.54)

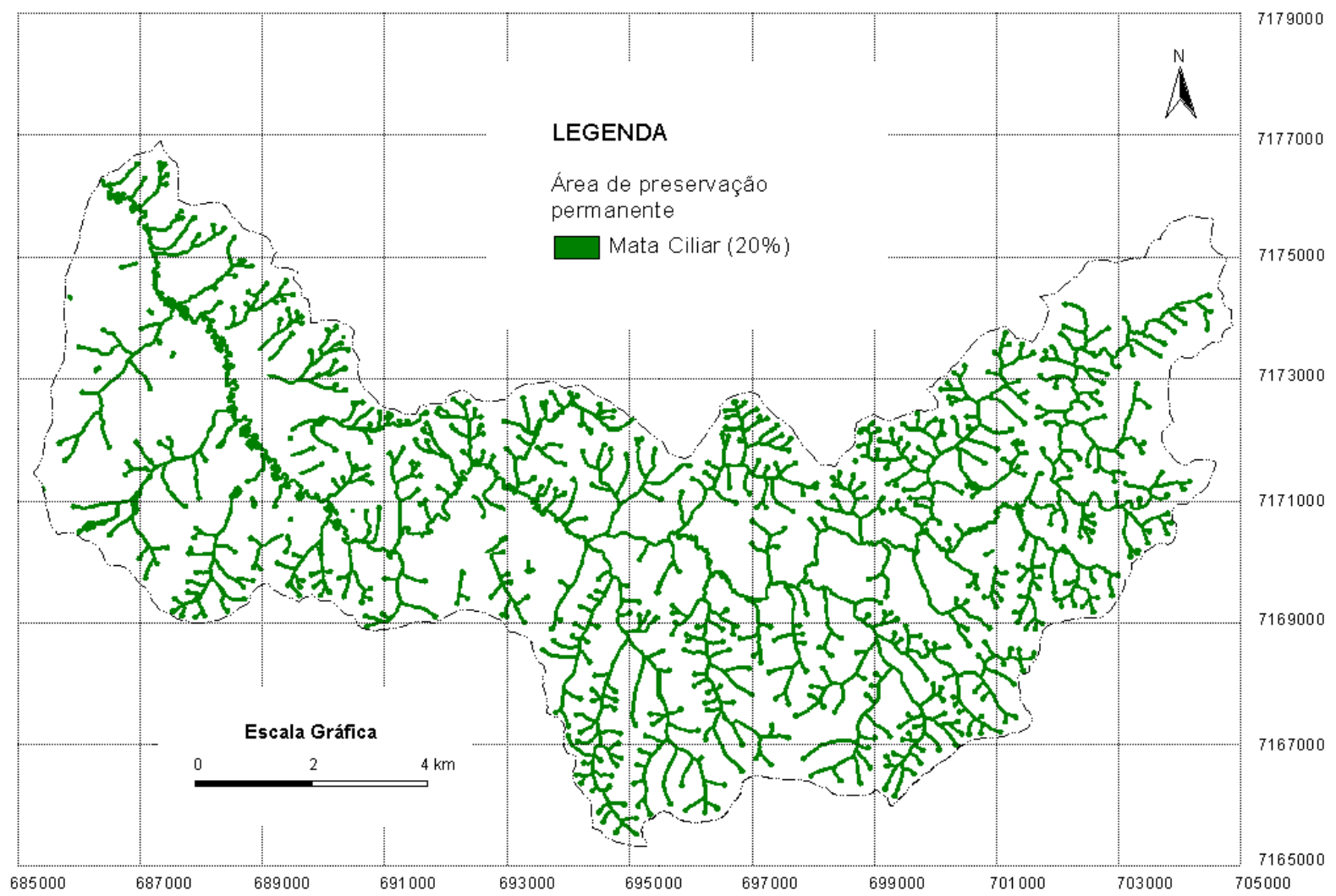

Figura 7. Mapa de áreas de preservação permanente.

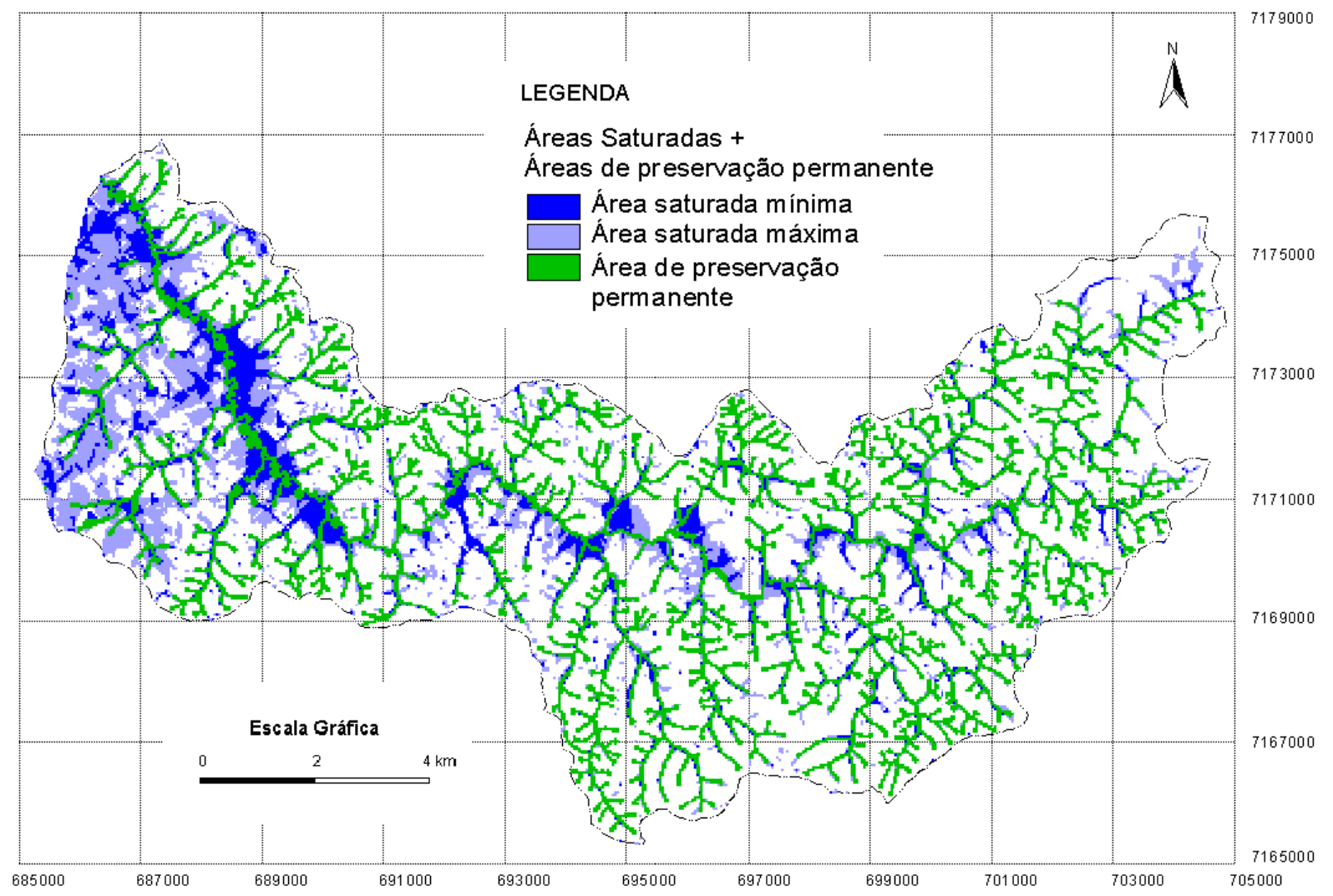

Figura 8. Comparação entre áreas de preservação permanente e áreas saturadas. 


\section{CONCLUSÕES}

O TOPMODEL respondeu de forma bastante eficiente às condições ambientais da área de estudo, confirmando a aplicabilidade desse modelo em regiões de clima úmido e relevo suave.

A medida de aderência entre as vazões observadas e simuladas, que indica a qualidade da simulação, resultou em um valor $E \cong 0,7$, ficando acima desse valor em quatro dos seis períodos simulados. Esse resultado indica alta eficiência no ajuste do modelo.

De maneira geral, os valores dos parâmetros de entrada do TOPMODEL ficaram muito próximos dos valores calculados previamente, ou seja, mantiveram-se coerentes com as grandezas físicas às quais estão associados. $\mathrm{O}$ modelo apresentou sensibilidade à inconsistência dos dados observados de precipitação, ressaltando a necessidade de dados observados de boa qualidade e com discretização temporal adequada.

No período simulado, a porcentagem de áreas saturadas em relação à área total da bacia variou entre $15,8 \%$ e 32,8\%. O valor mínimo de 15,8\% manteve-se constante durante os períodos mais secos e, apesar de aparentemente alto, está coerente com o observado na bacia, pois a configuração topográfica dela favorece a formação de banhados.

O modelo utilizado mostrou grande potencial de aplicabilidade no planejamento ambiental, pois permite discutir e orientar as ações antrópicas sobre o meio físico com base no entendimento dos processos naturais. Portanto, esse modelo torna-se uma ferramenta de grande utilidade para o diagnóstico e análise ambiental, bem como para subsidiar projetos de ordenamento territorial.

\section{REFERÊNCIAS}

BEVEN, K. J. Rainfall-runoff modelling: the primer. New York: J. Willey, 2001. 360 p.

BEVEN, K. J. TOPMODEL User Manual - Windows Version 97.01. Lancaster: Universidade de Lancaster, 1997. Disponível em: < http://www.es.lancs.ac.uk/hfdg/ topmodel.html>. Acesso em maio 2008.

BEVEN, K. J.; KIRKBY, M. J. A physically based, variable contributing area model of basin hydrology. Hydrological Sciences Bulletin, v. 24, p. 43-69, 1979.

BEVEN, K. J; LAMB, R.; QUINN, P.; ROMANOWICIZ, R.; FREER, J. Topmodel. In: SINGH, V. P. (Ed.) Computer models of watershed hydrology. Highlands Ranch: Water Resource Publication, 1995. p. 627-668.

COMPANHIA DE DESENVOLVIMENTO DO PARANÁ - CODEPAR. Folha geológica de São José dos Pinhais. Curitiba: CODEPAR, 1967. 1 Mapa. Escala 1:50.000.

DOORENBOS, J.; PRUIT, W.O. Crop water requirements. Roma: FAO, 1992. 144 p.

HORNBERGER, G. M.; RAFFENSPERGER, J. P.; WIBERG, P. L.; ESHLEMAN, K. N. Elements of physical hydrology. Baltimore: J. Hopkins, 1998. 302p.

INSTITUTO AGRONÔMICO DO PARANÁ - IAPAR. Cartas climáticas do estado do Paraná. Londrina: IAPAR, 1994.

IORGULESCU, I.; JORDAN, J. P. Validation of TOPMODEL on a small Swiss catchment. Journal of Hydrology, v. 159, p. 255-273, 1994. 
KIRKBY, M. J. Hillslope hydrology. Chichester: John-Wiley, 1978. 389p.

MAACK, R. Geografia física do estado do Paraná. Curitiba: Papelaria Roesner, 1968. 350p.

MINE, M.R.M. Método determinístico para minimizar o conflito entre gerar energia e controlar cheias. 1998. 146f. Tese (Doutorado em Recursos Hídricos) - Universidade Federal do Rio Grande do Sul, Porto Alegre, 1998.

MINE, M. R. M.; CLARKE, T. R. O uso do TOPMODEL em condições brasileiras: resultado preliminar. Revista Brasileira de Recursos Hídricos, Porto Alegre, v. 1, n. 2, p. 89106, 1996.

MONTGOMERY, D. R.; DIETRICH, W. E. Hydrologic processes in a low-gradient source area. Water Resources Research, v. 31, n. 1, p. 1-10, 1995.

SANTOS, I. Modelagem geobiohidrológica como ferramenta no planejamento ambiental: Estudo da bacia hidrográfica do Rio Pequeno, São José dos Pinhais PR. 2001. 92f. Dissertação (Mestrado em Ciências do Solo) - Universidade Federal do Paraná, Curitiba, 2001.

TUCCI, C. E. M. Modelos hidrológicos. Porto Alegre: ABRH, 1998. 669 p.

VARELLA, R. F.; CAMPANA, N. C. Simulação matemática do processo de transformação de chuva em vazão: estudo do modelo TOPMODEL. Revista Brasileira de Recursos Hídricos, Porto Alegre, v. 5, n. 4, p. 121-139, 2000.

WU, W.; SIDLE, R. C. A distributed slope stability model for steep forested basins. Water Resources Research, v. 31, n. 8, p. 2097-2110, 1995. 